\title{
V026 3D SEISMIC VOLUME INTERPRETATION FOR RESERVOIR CHARACTERIZATION - A NIGERIAN FIELD CASE STUDY
}

D.O. OWOLABI

Shell International Exploration \& Production BV, PO Box 162, 2501 AN The Hague, The Netherlands

Detailed understanding of the reservoir properties and hydrocarbon distribution pattern within a Nigerian field complex has been one of the main uncertainties affecting the development. To help in this aspect, 3D visualisation and seismic attribute work was carried out as part of an integrated study.

The field consists of four rollover anticlines separated by shallow saddles. The reservoirs comprise channel and shoreface deposits including coal layers. Some of the reservoirs have known common contacts across the four structures while others are restricted to a.part of the complex mainly in the south west area. Production data from over 200 drainage points showed uneven sweep of the hydrocarbon which could not be easily accounted for by the previous geological model based on 2D seismic data.

Normal 3D seismic mapping resulted in adequate structural configuration which in turn led to a better understanding of the hydrocarbon distribution. Detailed attribute analysis by correlation with well data helped in mapping sand development. The resulting correlation was then used in the calibration of the seismic attributes.

Volume interpretations showed variations in acoustic impedance properties within the field. By setting appropriate threshold cut off for visualising the data, the significant geological bodies have been tracked. With bodychecking, the connectivity of these geological features in 3D space has been assessed. The lack of connectivity between the fields at shallow reservoir levels could explain the different hydrocarbon accumulation conditions at these levels. The isolated sand body in the northern flank of the $\mathrm{O} 7.0$ reservoir has been shown to be the reason for the difference in the original hydrocarbon contacts.

Production from these intervals has been related to the distribution of the sand bodies. The result of the volume interpretation has been useful in understanding the reservoir sweep efficiency. This has been used to optimise further field development. 
